\title{
Psychiatric Emergencies of Asylum Seekers; Descriptive Analysis and Comparison with Immigrants of Warranted Residence
}

\author{
Georgios Schoretsanitis ${ }^{1,2, *(1)}$, Sarah Eisenhardt ${ }^{1}$, Meret E. Ricklin ${ }^{3}$, David S. Srivastava ${ }^{3}$, \\ Sebastian Walther ${ }^{1}$ and Aristomenis Exadaktylos ${ }^{3}$ \\ 1 University Hospital of Psychiatry, 3008 Bern, Switzerland; saraheisenhardt11@googlemail.com (S.E.); \\ sebastian.walther@puk.unibe.ch (S.W.) \\ 2 Department of Psychiatry, Psychotherapy and Psychosomatics, and JARA-Translational Brain Medicine, \\ RWTH Aachen University, 52074 Aachen, Germany \\ 3 Department of Emergency Medicine, Inselspital, University Hospital Bern, Freiburgstrasse, 3010 Bern, \\ Switzerland; meret.ricklin@gmail.com (M.E.R.); DavidShiva.Srivastava@insel.ch (D.S.S.); \\ Aristomenis.Exadaktylos@insel.ch (A.E.) \\ * Correspondence: george.schor@gmail.com; Tel.: +41-31-930-9111
}

Received: 12 May 2018; Accepted: 19 June 2018; Published: 21 June 2018

\begin{abstract}
Background: The aim of our study was to assess utilization patterns of psychiatric services by asylum seekers. Methods: We included 119 adults who presented themselves at the University Emergency Department between 1 March 2012 and 1 January 2017 for psychiatric consultation. Descriptive data were compared with a control group of non-Swiss individuals with warranted residence permits using Mann-Whitney- $U$ and chi square $\left(\chi^{2}\right)$ tests. Results: Patients were mainly single, male, residing in reception centers, and presented themselves most frequently due to suicidal ideation. Almost $60 \%$ of the patients were assigned to inpatient treatments, with 28 involuntary cases. Compared to the control group, asylum seekers were younger and more often men $(p<0.001$ for both). Further, they less often had family in Switzerland $\left(\chi^{2}=9.91, p=0.007\right)$. The proportion of patients coming in as walk-ins was significantly higher in the control group than in asylum seekers $\left(\chi^{2}=37.0, p<0.001\right)$. Asylum seekers were more frequently referred due to suicidal ideation and aggressive behavior than participants in the control group $\left(\chi^{2}=80.07, p<0.001\right)$. Diagnoses for asylum seekers infrequently included mood, as they often reported stress-related disorders $\left(\chi^{2}=19.6\right.$, $p=0.021)$ and they were infrequently released home $\left(\chi^{2}=9.19, p=0.027\right)$. Conclusion: Asylum seekers more frequently demonstrated severe symptoms such as suicidal ideation and aggressive behavior and they were mainly treated as inpatients, potentially due to minimal social resources.
\end{abstract}

Keywords: asylum seekers; psychiatric emergency services; involuntary treatment; psychiatric hospitalization

\section{Introduction}

The movement of people currently observed worldwide is comparable in size to the migration during/after the Second World War [1]. In Switzerland, the annual number of asylum seekers from 2008-2013 has remained stable between 40,000 and 43,000 per year, but has substantially increased during the following two years to over 65,000 new applications per year [2].

The vulnerability of asylum seekers and generally displaced persons in terms of mental health issues has been consistently described [3,4]. Despite the methodological inconsistency, there are several studies that suggest an enhanced prevalence of post-traumatic stress disorder and depression among 
refugees [5]. The factors that account for the deleterious effects of the refugee experience include pre-, peri- and post-migration adversities [6-8].

Epidemiological data of psychiatric emergency services' usage by refugees are now increasingly available and provide a valuable indication of the problems refugees experience [9-12]. This evidence may be instrumental in evolving strategies for improvement of psychiatric services. At the same time, major challenges such as cultural and language barriers need to be addressed [7,13]. Utilization patterns among immigrants in general have already been assessed in the Swiss context [14-16]. Nevertheless, data for asylum seekers are particularly scarce. But information is strongly needed, since refugees and asylum seekers, often considered as a homogenous sample, present prominent differences regarding the psychopathology patterns and prevalence of mental disorders [10,17-19]. Differences also refer to the living arrangements, since asylum seekers in Switzerland mainly, but not exclusively, live in asylum centers. Detention in reception centers has been also connected with a considerable mental health burden [20]. Nevertheless, the majority of claimants face particular problems in accessing mental health services, and frequently, the only available option is a psychiatric consultation in the emergency department. Moreover, it is absolutely worthwhile to study psychiatric emergencies among asylum seekers following the rise in annual numbers of asylum seekers during the past few years (2015-2016). This increase enables a larger-scale epidemiological research, which can focus on particular dimensions of the mental healthcare for asylum seekers, such as the order of compulsory treatment. Such epidemiological data exist mainly for heterogeneous samples of patients, poorly defined as of non-Western or black origin or/and lacking further information of residency status [21-24].

The main aim of this study was to provide first descriptive data on usage of psychiatric emergency services by asylum seekers. We also compared categorical outcomes between asylum seekers and immigrants with residence permits to identify factors that may distinguish these two groups of non-Swiss people.

\section{Materials and Methods}

This descriptive study included retrospective data from adult asylum seekers (age $\geq 18$ years). These individuals were admitted to the University Emergency Department (UNZ) for a psychiatric consultation between the 1 May 2012 and 28 February 2017. The UNZ consists of an organization, which provides $24 \mathrm{~h} /$ day psychiatric emergency services and it is responsible for the emergency mental healthcare for the Canton Bern (roughly 1 million citizens) including asylum centers in this catchment area. Consultations were conducted by resident doctors (medical doctors during the psychiatry training program) under supervision of senior doctors. Electronic medical records of patients with migratory background (i.e., non-Swiss nationality) were initially identified. These medical records have fastidiously been scrutinized for asylum seekers leading to 1697 records of patients with migratory background, i.e., non-Swiss nationality. Across asylum seekers there were individuals with pending cases (permit $\mathrm{N}$ ), persons with rejected asylum application and provisionally admitted refugees (permit F). The last category consisted of foreign nationals, ordered to return to their native countries, but, in those cases, such returners were not admissible, reasonable or possible [25]. These last two subgroups experience different stressors, and were, therefore, also excluded, yielding a final sample of 119 patients (See Figure 1). During the screening process, we identified 1460 medical records of patients with migratory background and warranted residence permits. After removing duplicates and rudimentary records, we identified 1104 patients, who were included in the analysis as the control group.

We were able to extract the following demographic and clinical data from the included medical records: gender, age, nationality, marital status, children, type of residence (reception center or not), the pathway to care (health professionals involved in the referral), the reason for presentation/referral, diagnosis at the time of consultation (according to ICD-10), referral outcome, presence of interpreter during the consultation and contact with psychiatric services prior to the recorded (current) consultation. While classifying patients according to their pathway to care, the following categories 
were formed: walk-in, general practitioner or other medical doctor (MD), ambulance, police, or reception centers. Note that during the asylum process, the Swiss government provides healthcare coverage on a mandatory basis; everyone is entitled access to a general practitioner. The reasons for presentation/referral were grouped as follows: suicidal thoughts, suicide attempt, auto-aggressive behavior, aggression, mood (depression) symptoms, sleep disorders, acute stress, somatic complaints, psychotic symptoms, psychosocial problems and medication acquisition. If a patient has been registered for more than one reason, the major concern at the time of presentation/referral was used as the main criterion for the outcome. In particular, when suicidal and depressive symptoms co-existed, patients were classified as referred due to suicidal ideation since they were more likely to be referred mainly due to the suicidal than depressive symptoms. Therefore, all patients classified as having depressive symptoms were unlikely to have reported suicidal ideation. Following up on the referral process the possible outcomes were admittance to a psychiatric clinic (voluntary or compulsory) or discharge home. Individuals with rudimentary case files or incomplete medical records were excluded from the analysis. Moreover, for patients who visited the UNZ more than once, only the most recent registration was considered. Based on a rough geographical classification, the origin countries have been formed into six groups; Middle East (Iran, Iraq, Jordan, Lebanon, Syria, Turkey, United Arab Emirates), Eastern Europe (Albania, Belarus, Bosnia-Herzegovina, Chechnya, Macedonia, Kosovo, Russia), sub-Saharan Africa (Angola, Benin, Congo, Eritrea, Ethiopia, Guinea, Nigeria, Somalia, Sudan, Togo), northwestern Africa (Algeria, Libya, Morocco, Tunisia), Central-South Asia (Afghanistan, Bangladesh, China, Sri Lanka).
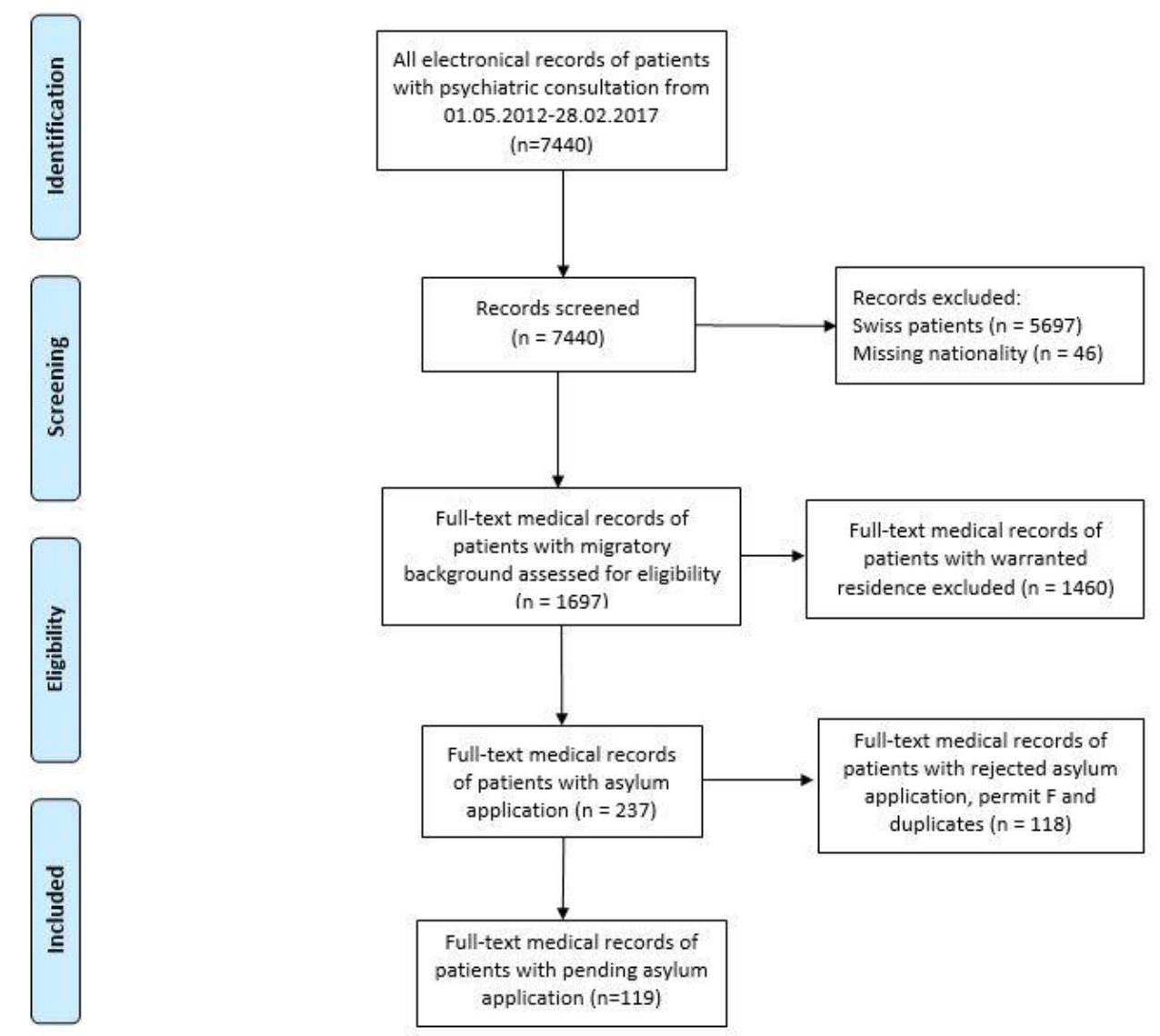

Figure 1. Medical records included in the analysis.

The study was performed retrospectively with health-related patient data that were exported anonymously for analysis. One of the authors (MER) had access to identification patient information and none of the authors was potentially a treating physician of the patients involved. Retrospective 
analysis of data for this study was in accordance with the local regulatory authority with the Declaration of Helsinki. No informed consent was necessary for this type of study.

\section{Statistical Analysis}

The data were summarized using descriptive statistics (means and standard deviation). We assessed gender, age, type of residence, referral conditions (reason and referring person), presence of an interpreter and prior contact to psychiatric services. Diagnoses (ICD-10) were classified into diagnostic categories (F10-19, 20-29, 30-39, 40-49, F60-69, F90-99). Demographic characteristics and parameters related to the registered consultation were compared between the group of asylum seekers and a control group of non-Swiss patients with warranted permits: our primary hypothesis was that involuntary treatment orders would be increased in the group of asylum seekers due to issues of integration; we studied referral outcomes as a categorical variable, but we also transformed referral outcomes to a dichotomous variable with ' 0 ' for cases of non-compulsory treatment consisting of discharge home and voluntary admissions in the clinic. We used the variable ' 1 ' for compulsory treatment consisting of involuntary admissions. The comparison between study groups was based on non-parametrical tests Mann-Whitney- $U(\mathrm{M}-\mathrm{W}-U)$ test and the chi square test $\left(\chi^{2}\right)$ with a significance level of $p<0.05$. For the computation of possible correlations, cases without data were excluded. All statistical analyses were carried out using IBM SPSS Statistics, version 22.0 (IBM GmbH, Ehningen, Germany).

\section{Results}

The medical records were scanned for asylum seekers leading to a sample of 119 persons (30 women, 89 men). The mean age was $29.88 \pm 9.13$ (range 18-57) years (Table 1). In terms of origin, individuals came from a wide range of countries; the most common origin countries were Eritrea $(n=17)$, Afghanistan $(n=14)$ and Morocco $(n=12)$ (Table 2). The majority of the patients were single $(n=67,56.3 \%)$ and 72 of the patients did not have children (60.5\%). Almost 6 out of 10 patients $(n=66,55.5 \%)$ had no relatives in Switzerland. Asylum seekers lived mainly in reception centers $(n=85,71.4 \%)$.

Table 1. Sociodemographic characteristics of asylum seekers $(n=119)$ and control group $(n=1104)$.

\begin{tabular}{|c|c|c|}
\hline & Asylum Seekers & Control Group \\
\hline Females (\%) & $30(25.2) *$ & $500(45.3)$ \\
\hline Age (SD) & $29.88(9.13) * *$ & $36.98(12.81)$ \\
\hline \multicolumn{3}{|c|}{ Marital status (\%) } \\
\hline Never been married & $67(56.3)^{* * *}$ & $458(41.5)$ \\
\hline Widowed \& Divorced & $9(7.5)$ & $210(19.0)$ \\
\hline Married (Spouse in $\mathrm{CH}$ ) & $13(10.9)$ & $227(20.6)$ \\
\hline Married (Spouse abroad) & $11(9.2)$ & $101(9.1)$ \\
\hline Unknown & $19(16.0)$ & $108(9.8)$ \\
\hline \multicolumn{3}{|c|}{ Children (\%) } \\
\hline No & $72(60.5)$ & $609(55.2)$ \\
\hline Yes (Children in $\mathrm{CH}$ ) & $18(15.1)^{* * * *}$ & $348(31.5)$ \\
\hline Yes (Children abroad) & $10(8.4)^{* * * *}$ & $33(3.0)$ \\
\hline Unknown & $19(16.0)$ & $114(10.3)$ \\
\hline \multicolumn{3}{|c|}{ At least one relative in $\mathrm{CH}$, not partner $(\%)$} \\
\hline No & $66(55.5)$ & $521(47.2)$ \\
\hline Yes & $34(28.6) * * * * *$ & $470(42.6)$ \\
\hline Unknown & $19(16.0)$ & $113(10.2)$ \\
\hline
\end{tabular}


Table 2. Regions of origin for asylum seekers $(n=119)$.

\begin{tabular}{cc}
\hline \multicolumn{2}{c}{ Regions of Origin (\%) } \\
\hline Middle East & $27(22.9)$ \\
Eastern Europe & $11(9.3)$ \\
Sub-Saharan Africa & $33(28.0)$ \\
Northwestern Africa & $26(22.0)$ \\
Central-South Asia & $21(17.8)$ \\
\hline
\end{tabular}

Predominantly, patients came as walk-ins patients $(n=52,43.7 \%)$, whereas 35 patients $(29.4 \%)$ were referred to the UNZ by the police (Table 3). The most frequent reason of referral was suicidal ideation, reported by 30 patients $(25.2 \%)$, followed by aggressive behavior, which was the referral reason for 25 patients (21.0\%). Seventy patients reported prior contact to psychiatric services $(58.8 \%)$. The consultation was aided by interpreting service in 29 cases $(24.4 \%)$ or by the presence of a person who was a speaker of the patient's native language (family member or colleague of the patient) in 9 cases $(7.6 \%)$, which was not possible in two thirds of the patients $(n=80,67.2 \%)$.

Table 3. Clinical characteristics of asylum seekers $(n=119)$ and control group $(n=1104)$.

\begin{tabular}{|c|c|c|}
\hline Variable & Asylum Seekers & Control Group \\
\hline \multicolumn{3}{|c|}{ Pathway to UNZ (\%) } \\
\hline Walk-in & $52(43.7) *$ & $653(59.1)$ \\
\hline General practitioner (or other MDs) & $16(13.4)$ & $101(9.1)$ \\
\hline Ambulance & $13(10.9)$ & $105(9.5)$ \\
\hline Police & $35(29.4)$ & $245(22.2)$ \\
\hline Reception center & $3(2.5)$ & NA \\
\hline \multicolumn{3}{|c|}{ Referral reason } \\
\hline Suicidal ideation & $30(25.2) * *$ & $122(11.1)$ \\
\hline Suicide attempt & $3(2.5)$ & $43(3.9)$ \\
\hline Auto-aggressive behavior & $7(5.9)$ & $15(1.4)$ \\
\hline Aggressive behavior & $25(21.0)^{* *}$ & $103(9.3)$ \\
\hline Psychotic symptoms & $11(9.2)^{* *}$ & $186(16.8)$ \\
\hline Depressive symptoms & $10(8.4)^{* *}$ & $172(15.6)$ \\
\hline Sleep disorders & $8(6.7)$ & $60(5.4)$ \\
\hline Acute stress & $9(7.6)$ & $91(8.2)$ \\
\hline Somatic complaints & $10(8.4)$ & $73(6.6)$ \\
\hline Psychosocial problems & $2(1.7)$ & $186(16.8)$ \\
\hline Medication acquisition & $2(1.7)$ & $7(0.6)$ \\
\hline Manic symptoms & $0(0)$ & $9(0.8)$ \\
\hline Addiction & $0(0)$ & $23(2.1)$ \\
\hline Other & $2(1.7)$ & $14(1.3)$ \\
\hline \multicolumn{3}{|c|}{ ICD diagnoses } \\
\hline Disorders due to substance use (F10-19) & $14(11.8)$ & $153(13.9)$ \\
\hline Disorders of schizophrenia spectrum (F20-29) & $22(18.5)$ & $243(22.0)$ \\
\hline Affective disorders (F30-F39) & $17(14.3) * * *$ & $256(23.2)$ \\
\hline Stress-related disorders (F40-F49) & $58(49.6)^{* * *}$ & $398(36.1)$ \\
\hline Personality disorders (F60-69) & $6(5.0)$ & $26(2.4)$ \\
\hline Others & $1(0.8)$ & $23(2.1)$ \\
\hline \multicolumn{3}{|c|}{ Referral outcome (\%) } \\
\hline Discharged home & $32(26.9)^{* * * *}$ & $453(41.0)$ \\
\hline Discharged home with outpatient treatment & $16(13.4)$ & $110(10.0)$ \\
\hline Voluntary admission & $42(35.3)$ & $312(28.3)$ \\
\hline Compulsory admission & $29(24.4)$ & $229(20.7)$ \\
\hline
\end{tabular}

N*** $\chi^{2}=9.19, \mathrm{df}=3, p=0.027$. 
The diagnostic picture is dominated by adjustment disorders (F43.2), which comprised one fourth of the diagnoses ( $n=30,25.21 \%$ ). Twenty-two patients $(18.5 \%)$ received a diagnosis of schizophrenia spectrum disorders, whereas patients were diagnosed with affective and substance use disorders in $14.3 \%(n=17)$ and $11.8 \%(n=14)$ of the cases, respectively. Regarding the referral outcomes, $59.7 \%(n=71)$ of patients were treated as inpatients: 42 voluntary treatment cases and 29 compulsory treatment cases (Table 3).

The group of asylum seekers was compared with a control group of non-Swiss citizens with warranted residence permits in terms of demographic/clinical characteristics and consultation aspects (Table 1). The two groups showed significant differences for age and sex distribution; asylum seekers were younger $(p<0.001$ for $\mathrm{M}-\mathrm{W}-U)$, more often men $\left(\chi^{2}=17.64, \mathrm{df}=1, p<0.001\right)$ and less likely to have been married than participants in the control group $\left(\chi^{2}=22.57, \mathrm{df}=5, p<0.001\right)$. No differences between groups were reported in the proportion of patients having children; nevertheless, the proportion of asylum seekers with children abroad was higher than in the control group and asylum seekers less frequently reported children living in Switzerland than patients in the control group $\left(\chi^{2}=22.3, \mathrm{df}=3, p<0.001\right)$. Patients in the control group more frequently had relatives residing in Switzerland compared to asylum seekers $\left(\chi^{2}=9.91, \mathrm{df}=2, p=0.007\right)$.

Moreover, the two groups differed regarding referral conditions; the proportion of patients presenting as walk-ins was significantly higher for patients of the control group than asylum seekers $\left(\chi^{2}=37.0, \mathrm{df}=4, p<0.001\right)$. The rest of the referral conditions did not differ between groups $(p>0.05$ for $\chi^{2}$ except from referral by the reception center, where no counts were available in the control group and, therefore, no valid analysis was possible. When exploring potential differences in referral reasons between groups, we detected higher rates of suicidal ideation and aggressive behavior but lower rates of depressive and psychotic symptoms in asylum seekers $\left(\chi^{2}=80.07, \mathrm{df}=15, p<0.001\right.$ for all comparisons). No differences were reported for somatic complaints $(p>0.05)$, whereas analyses were not conducted for the rest of reasons due to small number of counts per reason and group. The ICD diagnoses set by consulting psychiatrists differed for mood disorders (F30-39) and stress-related disorders (F40-49), with the mood disorders occurring proportionally less often and the stress-related disorders occurred proportionally more often in asylum seekers compared to control group $\left(\chi^{2}=19.6\right.$, $\mathrm{df}=9, p=0.021)$. Regarding referral outcome, the proportion of asylum seekers released home was lower than in the control group $\left(\chi^{2}=9.19, \mathrm{df}=3, p=0.027\right)$. For assignment to compulsory treatment (using referral outcome as a binary variable), study groups did not demonstrate differences $\left(\chi^{2}=0.85\right.$, $\mathrm{df}=1, p>0.05)$.

\section{Discussion}

Our study provides a descriptive and comparative analysis of utilization of psychiatric services for asylum seekers with pending application. To our knowledge, our retrospective assessment adds to previous research because access to mental healthcare for immigrants remains scarce. Nevertheless, this particular subgroup has distinct mental health needs as these patients are exposed to additional mental health risks [26]. Our study, contrasting previous studies, uses the migration status rather than the country of birth or race as a determinant for mental health problems. To our knowledge, specific parameters, such as the order of a compulsory treatment for these individuals, were examined, whereas the main point widely evaded the focus of research. In this context, we chose to include all psychiatric diagnoses, while most of earlier studies focused on refugees with schizophrenic disorders, and particularly first-episode patients. Moreover, the criteria for compulsory admissions largely vary between and even within countries since they strongly depend on the current mental health legislation [27].

The profile of asylum seekers in our sample indicated younger and more often male individuals compared to the control group. They were mainly residing in reception centers and they had no family in Switzerland. Less than the half of patients presented themselves as walk-ins to the UNZ and the most common referral reason was suicidal ideation. Consultants most frequently set a stress-related 
diagnosis and arranged an inpatient treatment in $40 \%$ of the cases. Asylum seekers reported less family support with fewer relatives in Switzerland than controls.

Moreover, the two groups differed regarding referral conditions; the proportion of patients coming in as walk-ins was significantly higher in the control group than asylum seekers. Asylum seekers were consulted more often due to suicidal ideation or aggressive behavior, but less often for psychotic or depressive symptoms compared to controls. Mood disorders were diagnosed in a higher proportion of patients in the control group than in asylum seekers, whereas the rates of stress-related disorders were higher for asylum seekers. Finally, the proportion of individuals released home was smaller in the asylum seekers than in the control group and no differences were reported for assignment to compulsory treatment.

When interpreting these differences, the age difference between study groups seems to be a plausible finding. Regarding the difference pertaining to gender, previous evidence indicated female underrepresentation $[11,16,28,29]$. In our sample, this finding may be due to the two-fold higher percentages of men in asylum seekers during the years 2011-2015 [2]. Moreover, the high percentage of aggressive behavior as referral reason (almost one out of fourth) for asylum seekers may be accounted for by gender, as aggression is more common in men than in women [30]. The proportion of individuals consulted for suicidal ideation was higher for asylum seekers than for controls; a Danish psychiatric emergency service study also reported suicidal ideas as the most common referral reason for asylum seekers [11]. Likewise, hospital data reported high incidence of suicidal behavior in asylum seekers residing in reception centers in the Netherlands [31]. On the other hand, the low rates of asylum seekers referred for depressive symptoms may be due to the overrepresentation of stress-related disorders in our sample as well as in previous samples $[7,17,32]$, as stress-related disorders may imitate depression in terms of psychopathology [33]. Moreover, an essential amount of asylum seekers with depressive symptoms was classified in the subgroup referred for suicidal ideation. Thus, it would be more precise to say that rates of depressive symptoms without co-existing suicidal ideation were higher in the control group. Further, asylum seekers were less often visiting the UNZ as walk-ins; a previous Irish study reported that asylum seekers tended to visit general practitioners, who may act as primary mental healthcare providers, more frequently than did controls [17]. Alternatively, we speculated that asylum seekers are less familiar with the structure of the health care system in Switzerland, so that they might hesitate to directly visit the UNZ. For both options, the stigmatizing impact of psychiatry may account for the barriers of these individuals to access to mental healthcare [34]. Nevertheless, no differences were reported regarding alternative pathways to mental health care between groups. The finding of high prevalence of stress-related disorders in terms of set diagnoses is no surprise but is in alignment with previous evidence [11,17]. Further, it is also rather expected that a higher proportion of asylum seekers were assigned to inpatient treatment, which may be understood in light of the fact that they showed more severe symptoms such as suicidal ideation and aggressive behavior than the control group. Moreover, controls may have more social resources due to relatives also residing in the country. Thus, the limited social support may account for the higher rates of asylum seekers treated as inpatients. The assignment to inpatient treatment may also relate to the access problems to specific treatments for asylum seekers, which was reported previously in cohort studies, also in the Swiss context [14,35].

Asylum status failed to correlate with assignment to compulsory treatment in our sample. This major counter-intuitive finding introduces a riddle that may demand quantitative data to unravel mediating mechanisms. In a sample of unaccompanied refugee minors with insecure asylum status, researchers reported high rates of involuntary treatment for these individuals referred due to self-harm and suicidal behavior [32]. Nevertheless, in our sample, differences for involuntary treatment between study groups did not reach statistical significance despite the high prevalence of suicidal ideation for asylum seekers.

Anxiety levels for asylum seekers may be strongly related to language issues [29]. The usage of interpreting services in our sample was very low compared to a Danish study [11], which may introduce 
an important challenge for the improvement of the mental healthcare system. The ethnic distribution of the asylum seekers presented in the emergency department reflects the mosaic of ethnicities of people applying for asylum in the Canton of Bern during the past year (2016). The countries with the most applications included Afghanistan, Eritrea, Syria and Iraq [2].

Due to the retrospective analysis of this database, results must be interpreted with some caution. No standardized general and systemic medical history was taken. Parameters such as socio-economic status, length of stay in Switzerland before presentation, symptom severity and illness onset and duration, were barely provided and therefore could not be included in the analyses. Moreover, asylum seekers in Switzerland invariably are not allowed to work. As a result, we were not able to control for the effects of this variable, although the role of unemployment for compulsory admissions as well as for the psychopathology already has been demonstrated $[29,36]$. In addition, no data regarding the length of asylum procedure were provided; nevertheless, this parameter has been associated with an increased risk of mental disorders [37-39]. Lastly, the control group was not matched for demographic or clinical characteristics with the group of asylum seekers.

\section{Conclusions}

Concluding, our data imply that persons presented for psychiatric consultation had severe symptoms and were more likely than persons with permanent permit to be treated as inpatients. The treatment of this distinct patient subgroup introduces a public mental health challenge that needs to be addressed urgently. We strongly hope that this study may inspire the conduction of prospective studies providing a better overview of the mental health of asylum seekers and enabling the minimization of the application of compulsory admissions.

Author Contributions: G.S., S.E., M.E.R., D.S.S., S.W. and A.E. participated in the research design of the study. G.S. performed the initial statistical analyses and wrote the first article draft. S.W. suggested additional analyses and modifications to adjust to the style of this journal. All the authors contributed to the interpretation of data and approved the final manuscript.

Funding: No sources of funding were used for this manuscript.

Acknowledgments: Authors are particularly grateful to C. Ringer, S. Suker, A. Jungnickel, University Hospital of Psychiatry, Bern, Switzerland for their valuable feedback.

Conflicts of Interest: In the last 10 years, Sebastian Walther has received honoraria for serving as a speaker in educational programs from Eli Lilly, Janssen, Lundbeck, and Otsuka. He was an advisory board member for Lundbeck and Otsuka from 2015 to 2016. All other authors declare no conflicts of interest.

\section{References}

1. The UN Refugee Agency. U. Global Trends 2015; United Nations High Commissioner for Refugees: Geneva, Switzerland, 2016.

2. State Secretariat for Migration, Switzerland. Available online: https://www.sem.admin.ch/sem/de/home/ publiservice/statistik/asylstatistik/archiv/2016/11.html (accessed on 12 May 2018).

3. Fazel, M.; Wheeler, J.; Danesh, J. Prevalence of serious mental disorder in 7000 refugees resettled in western countries: A systematic review. Lancet 2005, 365, 1309-1314. [CrossRef]

4. Bhugra, D.; Gupta, S.; Bhui, K.; Craig, T.; Dogra, N.; Ingleby, J.D.; Kirkbride, J.; Moussaoui, D.; Nazroo, J.; Qureshi, A.; et al. Wpa guidance on mental health and mental health care in migrants. World Psychiatry Off. J. World Psychiatr. Assoc. 2011, 10, 2-10. [CrossRef]

5. World Health Organisation Regional Office for Europe. Policy Brief on Migration and Health: Mental Health Care for Refugees; World Health Organisation: Copenhagen, Denmark, 2015.

6. Carswell, K.; Blackburn, P.; Barker, C. The relationship between trauma, post-migration problems and the psychological well-being of refugees and asylum seekers. Int. J. Soc. Psychiatry 2011, 57, 107-119. [CrossRef] [PubMed]

7. Silove, D.; Sinnerbrink, I.; Field, A.; Manicavasagar, V.; Steel, Z. Anxiety, depression and PTSD in asylum-seekers: Assocations with pre-migration trauma and post-migration stressors. Br. J. Psychiatry J. Ment. Sci. 1997, 170, 351-357. [CrossRef] 
8. Hassan, G.; Ventevogel, P.; Jefee-Bahloul, H.; Barkil-Oteo, A.; Kirmayer, L.J. Mental health and psychosocial wellbeing of Syrians affected by armed conflict. Epidemiol. Psychiatr. Sci. 2016, 25, 129-141. [CrossRef] [PubMed]

9. Deans, A.K.; Boerma, C.J.; Fordyce, J.; De Souza, M.; Palmer, D.J.; Davis, J.S. Use of royal darwin hospital emergency department by immigration detainees in 2011. Med. J. Aust. 2013, 199, 776-778. [CrossRef] [PubMed]

10. Iversen, V.C.; Morken, G. Differences in acute psychiatric admissions between asylum seekers and refugees. Nord. J. Psychiatry 2004, 58, 465-470. [CrossRef] [PubMed]

11. Reko, A.; Bech, P.; Wohlert, C.; Noerregaard, C.; Csillag, C. Usage of psychiatric emergency services by asylum seekers: Clinical implications based on a descriptive study in Denmark. Nord. J. Psychiatry 2015, 69, 587-593. [CrossRef] [PubMed]

12. McColl, H.; Johnson, S. Characteristics and needs of asylum seekers and refugees in contact with London community mental health teams: A descriptive investigation. Soc. Psychiatry Psychiatr. Epidemiol. 2006, 41, 789-795. [CrossRef] [PubMed]

13. Sandhu, S.; Bjerre, N.V.; Dauvrin, M.; Dias, S.; Gaddini, A.; Greacen, T.; Ioannidis, E.; Kluge, U.; Jensen, N.K.; Lamkaddem, M.; et al. Experiences with treating immigrants: A qualitative study in mental health services across 16 European countries. Soc. Psychiatry Psychiatr. Epidemiol. 2013, 48, 105-116. [CrossRef] [PubMed]

14. Maier, T.; Schmidt, M.; Mueller, J. Mental health and healthcare utilization in adult asylum seekers. Swiss Med. Wkly. 2010, 140, w13110. [CrossRef] [PubMed]

15. Chatzidiakou, K.; Schoretsanitis, G.; Schruers, K.R.; Müller, T.J.; Ricklin, M.E.; Exadaktylos, A.K. Acute psychiatric problems among migrants living in switzerland- a retrospective study from a Swiss University emergency department. Emerg. Med. (Los Angel.) 2016, 6. [CrossRef]

16. Pfortmueller, C.A.; Schwetlick, M.; Mueller, T.; Lehmann, B.; Exadaktylos, A.K. Adult asylum seekers from the Middle East including Syria in Central Europe: What are their health care problems? PLoS ONE 2016, 11, e0148196. [CrossRef] [PubMed]

17. Toar, M.; O'Brien, K.K.; Fahey, T. Comparison of self-reported health \& healthcare utilisation between asylum seekers and refugees: An observational study. BMC Public Health 2009, 9, 214.

18. Ryan, D.A.; Benson, C.A.; Dooley, B.A. Psychological distress and the asylum process: A longitudinal study of forced migrants in Ireland. J. Nerv. Ment. Dis. 2008, 196, 37-45. [CrossRef] [PubMed]

19. Silove, D.; Steel, Z.; Susljik, I.; Frommer, N.; Loneragan, C.; Chey, T.; Brooks, R.; le Touze, D.; Ceollo, M.; Smith, M.; et al. The impact of the refugee decision on the trajectory of ptsd, anxiety, and depressive symptoms among asylum seekers: A longitudinal study. Am. J. Disaster Med. 2007, 2, 321-329. [PubMed]

20. Steel, Z.; Momartin, S.; Bateman, C.; Hafshejani, A.; Silove, D.M.; Everson, N.; Roy, K.; Dudley, M.; Newman, L.; Blick, B.; et al. Psychiatric status of asylum seeker families held for a protracted period in a remote detention centre in Australia. Aust. N. Z. J. Public Health 2004, 28, 527-536. [CrossRef] [PubMed]

21. Mulder, C.L.; Koopmans, G.T.; Selten, J.P. Emergency psychiatry, compulsory admissions and clinical presentation among immigrants to The Netherlands. Br. J. Psychiatry J. Ment. Sci. 2006, 188, 386-391. [CrossRef] [PubMed]

22. Norredam, M.; Garcia-Lopez, A.; Keiding, N.; Krasnik, A. Excess use of coercive measures in psychiatry among migrants compared with native Danes. Acta Psychiat. Scand. 2010, 121, 143-151. [CrossRef] [PubMed]

23. Davies, S.; Thornicroft, G.; Leese, M.; Higgingbotham, A.; Phelan, M. Ethnic differences in risk of compulsory psychiatric admission among representative cases of psychosis in London. BMJ 1996, 312, 533-537. [CrossRef] [PubMed]

24. Mann, F.; Fisher, H.L.; Major, B.; Lawrence, J.; Tapfumaneyi, A.; Joyce, J.; Hinton, M.F.; Johnson, S. Ethnic variations in compulsory detention and hospital admission for psychosis across four UK early intervention services. BMC Psychiatry 2014, 14, 256. [CrossRef] [PubMed]

25. State Secretariat for Migration, Switzerland. Available online: https://www.sem.admin.ch/sem/en/home/ themen/aufenthalt/nicht_eu_efta/ausweis_f__vorlaeufig.html (accessed on 12 May 2018).

26. Momartin, S.; Steel, Z.; Coello, M.; Aroche, J.; Silove, D.M.; Brooks, R. A comparison of the mental health of refugees with temporary versus permanent protection visas. Med. J. Aust. 2006, 185, 357-361. [PubMed]

27. Riecher-Rossler, A.; Rossler, W. Compulsory admission of psychiatric patients-An international comparison. Acta Psychiat. Scand. 1993, 87, 231-236. [CrossRef] [PubMed] 
28. Crepet, A.; Rita, F.; Reid, A.; Van den Boogaard, W.; Deiana, P.; Quaranta, G.; Barbieri, A.; Bongiorno, F.; Di Carlo, S. Mental health and trauma in asylum seekers landing in sicily in 2015: A descriptive study of neglected invisible wounds. Confl. Health 2017, 11, 1. [CrossRef] [PubMed]

29. Hocking, D.C.; Kennedy, G.A.; Sundram, S. Mental disorders in asylum seekers: The role of the refugee determination process and employment. J. Nerv. Ment. Dis. 2015, 203, 28-32. [CrossRef] [PubMed]

30. Witt, K.; van Dorn, R.; Fazel, S. Risk factors for violence in psychosis: Systematic review and meta-regression analysis of 110 studies. PLoS ONE 2013, 8, e55942. [CrossRef]

31. Goosen, S.; Kunst, A.E.; Stronks, K.; van Oostrum, I.E.; Uitenbroek, D.G.; Kerkhof, A.J. Suicide death and hospital-treated suicidal behaviour in asylum seekers in The Netherlands: A national registry-based study. BMC Public Health 2011, 11, 484. [CrossRef] [PubMed]

32. Ramel, B.; Taljemark, J.; Lindgren, A.; Johansson, B.A. Overrepresentation of unaccompanied refugee minors in inpatient psychiatric care. SpringerPlus 2015, 4, 131. [CrossRef] [PubMed]

33. McColl, H.; McKenzie, K.; Bhui, K. Mental healthcare of asylum-seekers and refugees. Adv. Psychiatr. Treat. 2008, 14, 452-459. [CrossRef]

34. Bartolomei, J.; Baeriswyl-Cottin, R.; Framorando, D.; Kasina, F.; Premand, N.; Eytan, A.; Khazaal, Y. What are the barriers to access to mental healthcare and the primary needs of asylum seekers? A survey of mental health caregivers and primary care workers. BMC Psychiatry 2016, 16, 336. [CrossRef] [PubMed]

35. Sundvall, M.; Tidemalm, D.H.; Titelman, D.E.; Runeson, B.; Baarnhielm, S. Assessment and treatment of asylum seekers after a suicide attempt: A comparative study of people registered at mental health services in a Swedish location. BMC Psychiatry 2015, 15, 235. [CrossRef] [PubMed]

36. Braam, A.W.; van Ommeren, O.W.; van Buuren, M.L.; Laan, W.; Smeets, H.M.; Engelhard, I.M. Local geographical distribution of acute involuntary psychiatric admissions in subdistricts in and around Utrecht, The Netherlands. J. Emerg. Med. 2016, 50, 449-457. [CrossRef] [PubMed]

37. Hollifield, M.; Warner, T.D.; Lian, N.; Krakow, B.; Jenkins, J.H.; Kesler, J.; Stevenson, J.; Westermeyer, J. Measuring trauma and health status in refugees: A critical review. JAMA 2002, 288, 611-621. [CrossRef] [PubMed]

38. Hallas, P.; Hansen, A.R.; Staehr, M.A.; Munk-Andersen, E.; Jorgensen, H.L. Length of stay in asylum centres and mental health in asylum seekers: A retrospective study from Denmark. BMC Public Health 2007, 7, 288. [CrossRef] [PubMed]

39. Sultan, A.; O'Sullivan, K. Psychological disturbances in asylum seekers held in long term detention: A participant-observer account. Med. J. Aust. 2001, 175, 593-596. [PubMed] 